\title{
THE DIAGNOSIS OF THE MITRAL LESION IN PATIENTS WITH REGURGITATION
}

\author{
P. G. F. Nixon, M.R.C.P. \\ Consultant Cardiologist to the Charing Cross Group of Hospitals; formerly Consultant Cardiologist to the \\ Department of Thoracic Surgery in the General Infirmary at Leeds
}

IT is common for patients with severe disability from chronic rheumatic mitral valvular disease to present with the apical pansystolic murmur of mitral regurgitation, and the planning of the surgical treatment depends upon the diagnosis of the lesion. Valvotomy may be carried out when the regurgitation is trivial and the obstruction severe, and the valve may be repaired in cases of predominant regurgitation if the aortic cusp is mobile. Prosthetic replacement of the valve may be the only possible treatment where immobility of the cusps and chordæ is associated with a mixture of obstruction and regurgitation.

It is reasonable to look for diagnostic principles in the relationships between the clinical and physiological abnormalities and the surgeon's findings at operation, but the author found little of value in attempts to relate the surgeon's opinion of the regurgitation to the systolic murmur, the systolic thrust of the apex of the left ventricle, the systolic expansion of the left atrium, the cardiographic and radiological evidence of left ventricular hypertrophy, the left atrial ' $v$ ' wave and ' $x$ ' and ' $y$ ' troughs, or to estimates of regurgitation made from indicator-dilution curves. Then, in 1957, McDonald and his colleagues made the point that a relationship must exist between the size of the mitral orifice and the severity of the regurgitation: the patients with the smallest orifices must be suffering from severe obstruction and little regurgitation, and the patients with the largest orifices must be suffering from severe regurgitation with little or no obstruction (McDonald, Dealy, Rabinowitz and Dexter, 1957). In practice it is easier to estimate the long diameter of the mitral orifice than its area (Goodwin, Hunter, Cleland, Davies and Steiner, 1955).

Anatomically, the mitral orifices encountered have measured anything from under $1 \mathrm{~cm}$. to more than $5 \mathrm{~cm}$. in their long diameter.

Physiologically, however, the findings have not placed the patients in a spectrum, or continuous series extending from one extreme of regurgitation to the other, but divided them into three distinct groups, namely, the group with the syndrome of obstruction, the group with the syndrome of incompetence, and the group with the syndrome of the rigid valve.

The purpose of this paper is to consider the physiological basis and the therapeutic implications of the grouping. It is to be emphasized that patients with severe disability and the apical murmur of mitral regurgitation are the subject of the paper, and not those with pure obstruction or slight disability, nor those with the complication of noteworthy ischæmic, hypertensive, or aortic valvular heart disease.

\section{The Technique of Investigation}

In the clinical examination the presence of mitral facies and peripheral cyanosis and coldness are noted because they occur much more frequently in severe obstruction than in severe incompetence. The arterial pulse is more likely to present a sharp percussion wave in incompetence than in obstruction. The signs of congestive heart failure, pulmonary hypertension, right ventricular enlarge ment and tricuspid incompetence indicate the severity and duration of the mitral lesion and no its nature.

The apical thrust of the left ventricle is recognized by its outward movement in systole, and distinguished from the systolic inward movement of the apex of the right ventricle (Mackenzie, 1902).

If the apex of the left ventricle is readily palpable the apical vibrations are attributed to the mitral lesion. A palpable third sound shock excludes severe obstruction, and a short thrill early in diastole is more likely to result from the torrential flow of mitral incompetence than from the impeded flow of severe obstruction.

If the apex beat is formed by the apex of the right ventricle the third sound and diastolic vibrations are probably caused by tricuspid incompetence, and the mitral lesion is more likely to be obstructive than incompetent.

The electrocardiagram is recorded. Usually it gives more information about the digitalis hypersensitivity and potassium depletion, and liability to post-operative cardiac arrest, of chronic diuretic treatment than it gives about the nature of the mitral lesion. In patients with giant left atria the signs of left ventricular enlargement are less often masked and the electrocardiogram has a greater diagnostic value (Nixon and Ikram, 1963).

A chest radiogram is examined for basal horizontal lines; they are commonly prominent in 


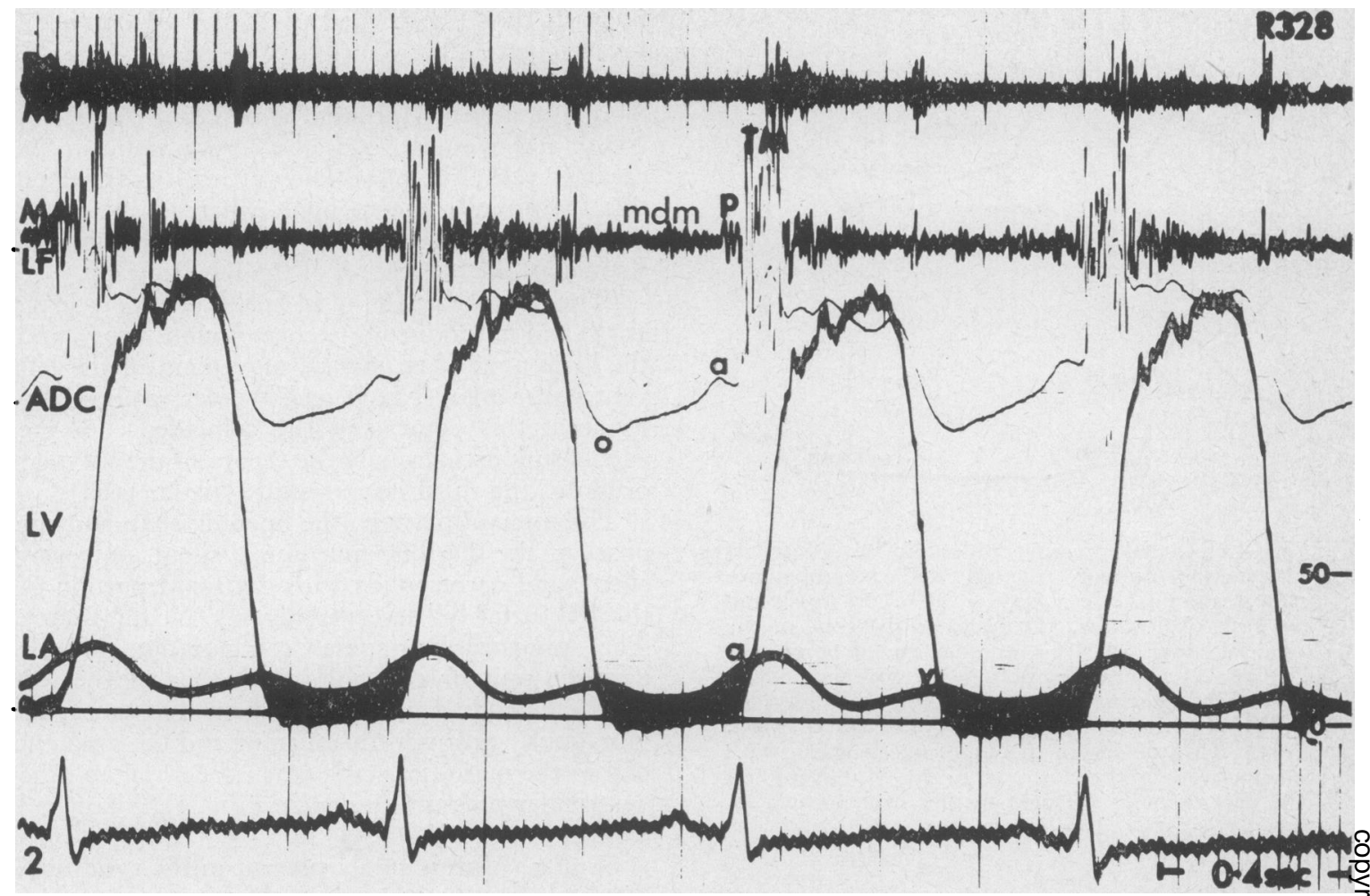

Fig. I. - The syndrome of severe mitral obstruction. Simultaneous pulmonary area (PA/MF) and mitral area (MA/LF) phonocardiograms, the displacement curve of the skin overlying the apex of the left ventricle (ADC), the left ventricular and left atrial pressure pulses (LV and LA) and the electrocardiogram (2). TM = tricuspid and mitral closure vibrations. mdm and $\mathrm{p}=$ mitral mid-diastolic and presystolic murmur. $\mathrm{a}=$ atrial wave of the apex curve and left atrial pulse. $v=$ atrial ' $v$ ' wave. $o=$ the mitral valve opening point. The shaded area between the pressure pulses indicates the left ventricular filling pressure gradient.

severe obstruction, but not in severe incompetence (Nixon and Ikram, 1964). A highly penetrated postero-anterior chest teleradiogram is taken to demonstrate the outline of the left atrium and to permit the estimation of its area by planimetry.

The pulmonary and the mitral area phonocardiograms (Leatham, 1952) are taken, and the simultaneous record of the inward-outward movement or displacement of the skin overlying the apex of the left ventricle is used as a reference tracing (Schneider and Klunhaar, 196r; Wooler, Nixon, Grimshaw, Watson, 1962; Nixon and Wooler, I963a).

Right and transeptal left heart catheterization is performed in the manner previously described (Nixon, 1960), and the left atrial pressure pulse is recorded simultaneously with the phonocardiogram. Blue dye is injected into the left atrium close to the fossa ovalis, and an arterial indicatordilution curve is obtained with an ear-piece (Nixon and Snow, 1962). At catheterization it is not necessary to enter the left ventricle because the configuration and the duration of the left ventricular filling pressure gradient can be deduced from the diastolic murmur and the left atrial pulse (Nixon and Wooler, I963a, b). The level of the left ventricular end-diastolic pressure is known to be similar to the left atrial stasis wave (Nixon and Wooler, I96r).

\section{The Syndrome of Severe Obstruction}

When the long diameter of the regurgitating mitral orifice measures about $1.5 \mathrm{~cm}$. or less the important physiological signs resemble those of severe obstruction without regurgitation.

The diastolic murmur begins quietly close to the opening snap, and alters little in loudness as it rumbles through diastole; if sinus rhythm is present the murmur vibrations are accentuated during atrial systole (Fig. I) (Hultgren and Leo, I959a, b; Nixon and Wooler, 1960; Nixon, 1961).

Third heart sounds do not occur (Nixon, I96r).

The apex of the left ventricle may or may not be palpable. When its movement can be recorded 

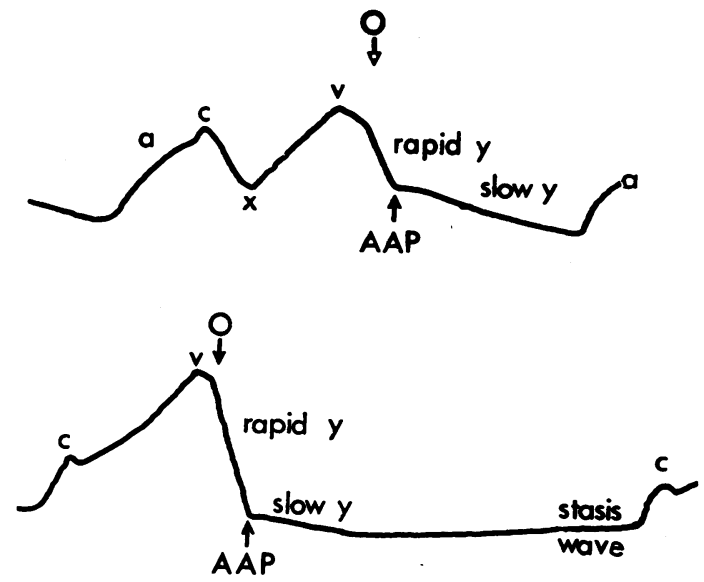

FIG. 2.-Left atrial pressure pulses in severe mitral obstruction (upper tracing) and incompetence (lower tracing). a, c, $v, x, y=$ ' $a$ ', ' $c$ ', 'v' waves and ' $x$ ' and ' $y$ ' descents. $O$ indicates the time of the opening snap. AAP $=$ annular ascent point. In the case of severe obstruction the slow part of the ' $y$ ' descent persists until it is interrupted by the first event of the next cardiac cycle, the ' $a$ ' wave. In the case of severe incompetence a stasis wave occurs between the slow part of the ' $y$ ' descent and the first event of the next cardiac cycle, which, in atrial fibrillation, is a 'c' wave.

from the overlying chest wall it may be observed to move outwards slowly in diastole without displaying a sharply peaked wave at the junction of the rapid and the slow phases of left ventricular filling (Fig. I) (Nixon and Wooler, r963a).

The left atrial pressure pulse is free from stasis waves, even in the longest diastolic intervals that may be found in patients with slow atrial fibrillation (Fig. 2) (Nixon and Wooler, 196r).

The abnormally large left ventricular filling pressure gradient persists throughout the longest diastolic intervals that can be recorded, and the level of the left ventricular diastolic pressure usually remains below the sternal angle (Fig. I) (Nixon and Wooler, 1963a, b).

When patients with giant enlargement of the left atrium are excluded it is found (Nixon and Snow, 1962) that the areas of the left atrial shadows are similar to those of pure obstruction, as are the various indices that may be obtained from the indicator-dilution curve, namely, the Hamilton and the Newman volumes; the mean circulation time; the ratio of least concentration to recirculation peak concentration (Wood and Woodward, 1957), and the spread/appearance time ratio (Shillingford, 1958).

\section{The Syndrome of Severe Incompetence}

The patients with regurgitating orifices measuring about $2.0 \mathrm{~cm}$. or more show signs that dis- tinguish them from those with the syndrome of severe obstruction.

The diastolic murmur begins abruptly with loud vibrations (Hultgren and Leo, r959a, b; Nixon and Wooler, 1960) at a certain point in the cardiac cycle (Fig. 3). Radner (1957, 1958) named this the annular ascent point when he described the effect on the left atrial pulse of the sudden early diastolic elongation of the left ventricle.

(The third heart sound in health (Radner, I957, 1958) and mitral incompetence (Nixon, 1961), and the beginning of an inward movement of the left ventricular apex (Nixon and Wooler, r963a) also occur at this point, and the coincidence of the events supports strongly the theory of the valvular origin of the third heart sound (Nixon, 1963).)

The interval between the opening snap and the onset of the diastolic murmur is silent, or nearly silent, and corresponds with the rapid portion of the left atrial 'y' descent (Fig. 4) (Nixon, I96r). The phonocardiographic configuration of the diastolic mumur resembles the shape of the left ventricular filling pressure gradient that causes its vibrations, and both the murmur and the gradient end in the period of stasis when the atrial and the ventricular pressures equalize, (Fig. 3) (Nixon and Wooler, i963a, b).

Sinus rhythm is rarely present in the syndrome of of severe incompetence, but when it is present the atrial contraction may enhance the flow across the mitral valve and produce a presystolic murmur indistinguishable from that of severe obstruction (Nixon and Wooler, I963a).

Third heart sounds occur at the onset of the diastolic murmur in the majority of heart cycles (Fig. 4) (Nixon, 196r).

Left atrial stasis waves may be seen in many of the cardiac cycles when the patient is free from tachycardia, and their height is an index to the degree of left ventricular failure caused by the incompetence (Nixon and Wooler, 196r).

The apex of the left ventricle moves outwards rapidly once the mitral valve has opened, and, at the end of the rapid filling period, is pulled inwards sharply. This rapid outward-inward movement is appreciated with the hand as the 'palpable third heart sound', and is a valuable physical sign of severe incompetence (Fig 4).

The abnormally large ventricular filling pressure gradient of mitral incompetence has two features that distinguish it from the gradient of severe obstruction. Firstly it may be demonstrated to end in the period of stasis in many heart cycles when there is freedom from tachycardia, and secondly, it is characterized by a rise of the ventricular pressure to an abnormally high level (Fig. 3) (Nixon and Wooler, 1963a, b).

At operation one group of these cases with the 


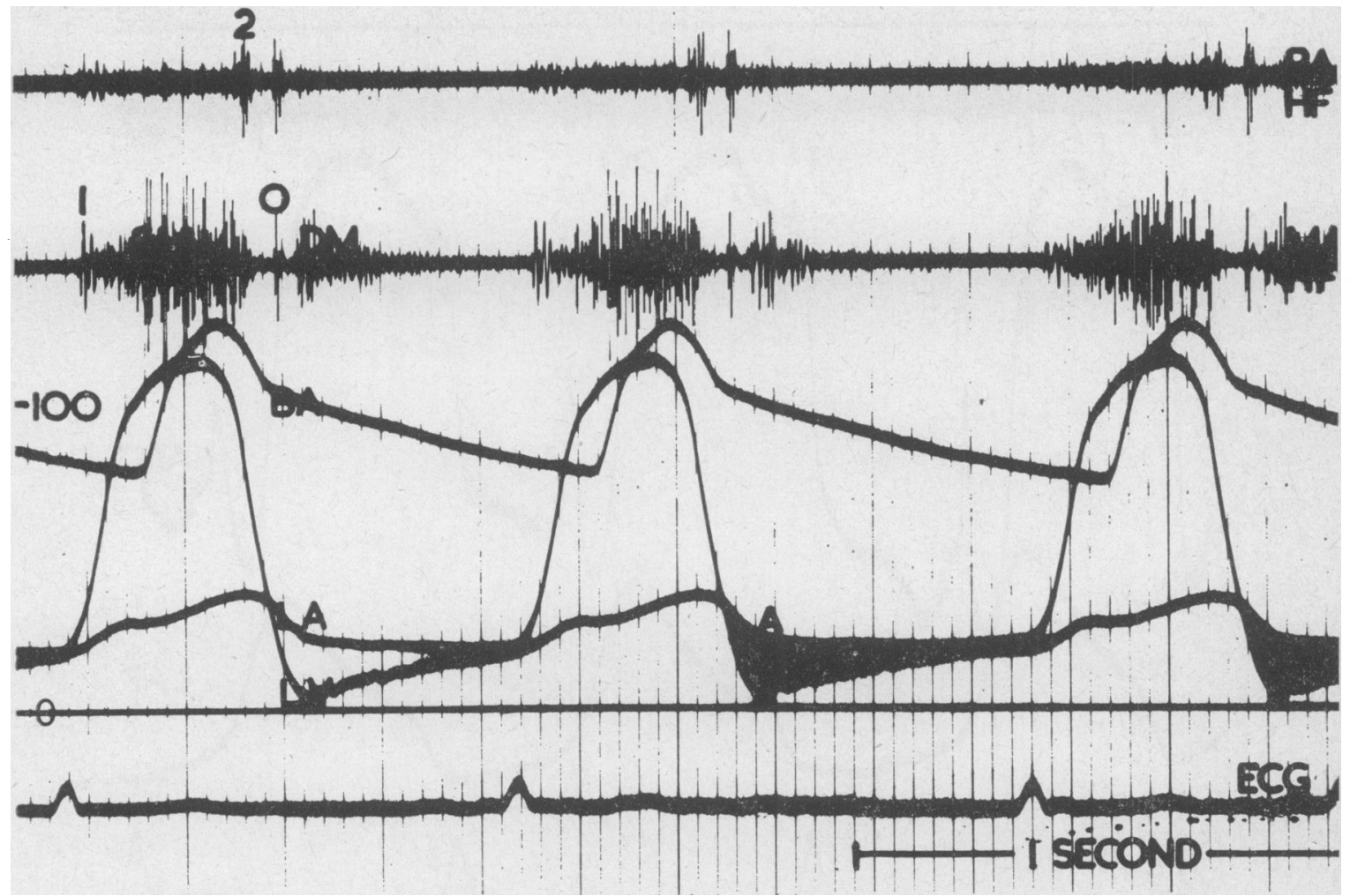

FIG. 3.-Severe mitral incompetence. Simultaneous pulmonary area (PA/HF) and mitral area (MA/HF) phonocardiograms; the brachial arterial (BA), left ventricular (LV) and left atrial (LA) pressure pulses, and the electrocardiogram (ECG). $1,2=$ Ist and 2 nd heart sounds. $O=$ mitral opening snap. $S M$ and $D M=$ mitral systolic and diastolic murmurs. $\mathrm{A}=$ annular ascent point. The shaded area between the pressure pulses indicates the left ventricular filling pressure gradient.

syndrome of severe incompetence is found to have 'pure' mitral incompetence, i.e. there is no element of adhesion between the cusps, and the orifice gapes widely open. The other group is found to have the orifice reduced, possibly to 2.0 to $2.5 \mathrm{~cm}$., by adhesions across the commissures; anatomically this group may be said to show 'an element of stenosis'. Physiologically there is no dividing line between the groups because they both have frequent third sounds, the characteristic diastolic murmur, left ventricular filling pressure gradient, and left ventricular apex tracing. The signs may be more florid in the cases with the larger orifices, but they are not different in kind.

\section{Indicator-dilution curves}

In mitral disease the indicator-dilution curve may be grossly abnormal (Fig. 5). There may be a reduction of the downslope of the primary curve (Korner and Shillingford, 1955), together with lowering of the peak concentration, prolongation of the time components, and dis- appearance of the re-circulation peak (Woodward, Burchell and Wood, r957). The abnormalities can result from enlargement of the left atrial residual volume, and they are particularly prominent in cases of mitral obstruction with aneurysmal enlargement of the left atrium (Nixon and Snow, 1962; Nixon and Ikram, 1963). The abnormalities can also result from the atrial enlargement, the reduced cardiac output, and the increased mixing of blood and indicator that occur in mitral regurgitation (Phinney, Cotton, Shillingford, I96I); and it may never be possible to decide how much of the abnormality of an arterial indicator-dilution curve is caused by atrial enlargement, and how much by the other effects of regurgitation. Dilution curves obtained by injecting indicator into the left ventricle and sampling blood from the left atrium have theoretical advantages and practical disadvantages (Nixon and Snow, 1962), and the author has not yet felt the need to employ them.

Two rules of thumb are helpful. If the left 


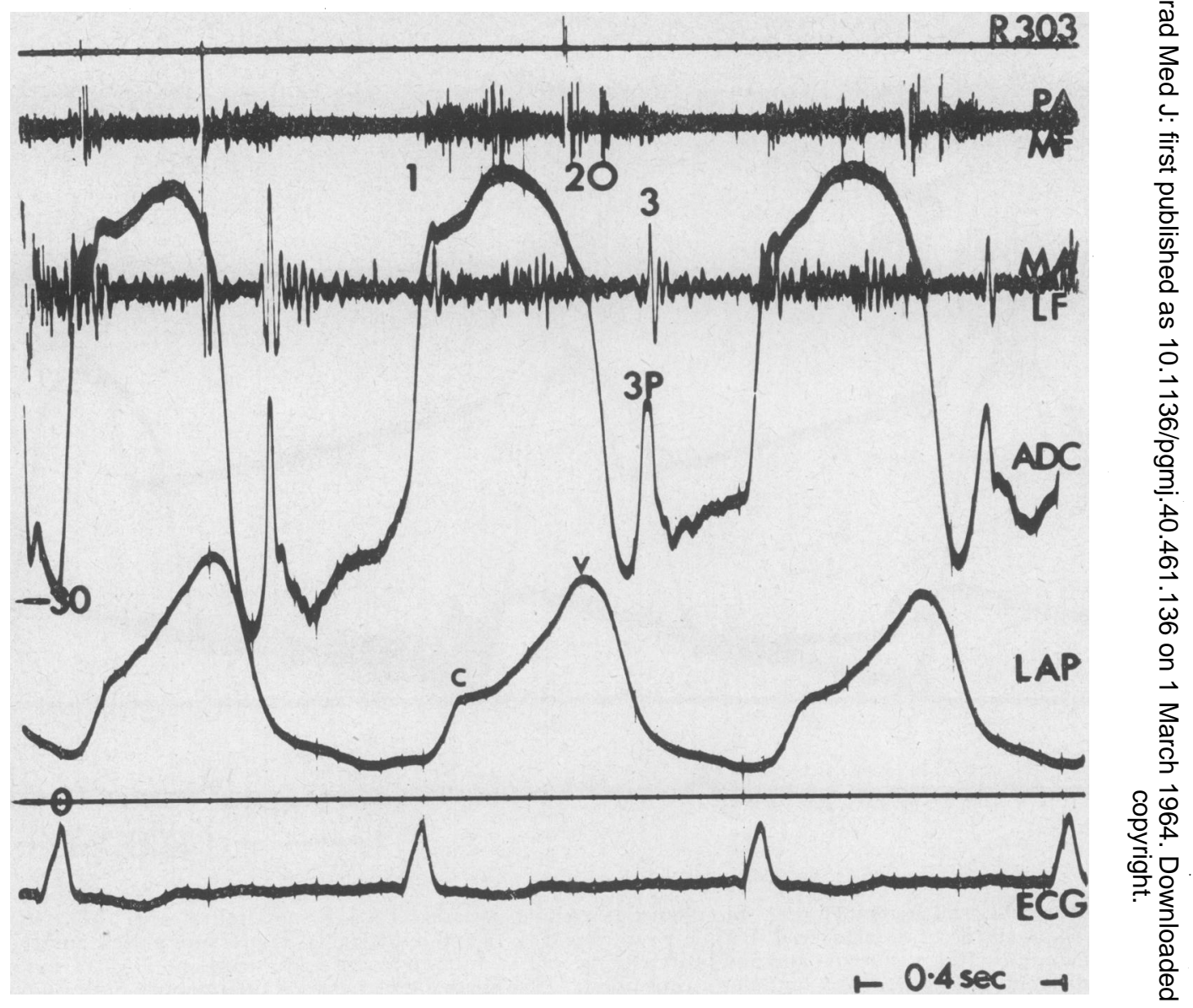

Fig. 4.-Severe mitral incompetence. Simultaneous pulmonary area (PA/MF) and mitral area (MA/LF) phonocardi $\vec{g}$ grams; the displacement curve of the skin overlying the apex of the left ventricle (ADC); the left atrial pressume pulse (LAP) and the electrocardiogram (ECG). I, 2, 3, $0=$ Ist, 2nd and 3 rd heart sounds and mitral opening snap. $\mathrm{C} \mathrm{V}=$ left atrial ' $\mathrm{C}$ ' and ' $\mathrm{V}$ ' waves. ${ }_{3} \mathrm{P}=$ the apex of the rapid outward-inward movement palpable $\frac{\text { git }}{8 t}$ the time of the third heart sound.

atrial area measures more than $100 \mathrm{~cm}^{2}$ and the dilution curve is grossly abnormal, examine the appearance time; it is likely to be normal or reduced in severe incompetence, and to be prolonged in severe obstruction (Shillingford, 1958, Nixon and Ikram, 1963). If the left atrial area measures less than $100 \mathrm{~cm}^{2}$ examine the dip of least concentration between the primary and the re-circulation peak: it is likely to be less than half the height of the re-circulation peak in severe obstruction, and to be barely discernible, or absent, in severe regurgitation.

\section{The mitral opening snap}

In severe mitral disease the opening snap is prominent when the major part of the aortic leaflet is pliant and mobile. It is common in severe obstruction and severe incompetence alike (Nixon, Wooler and Radigan, r960).
In severe incompetence a prominent snap is the rule rather than the exception in the cases with the largest orifices, where the leaflets are usuality healthy in spite of being separated widely by dilatation of the atrio-ventricular ring. If the opening snap is absent or almost absent in the syndrome of severe incompetence the orifice likely to measure 2 to $2.5 \mathrm{~cm}$., and the aortic cusp $\frac{\overline{\text { ts }}}{3}$ probably immobilised by fibrosis spreading from the commissural adhesions.

\section{The syndrome of the rigid valve}

In an experience of nearly 400 cases of mitral disease investigated by left heart catheterizatiơ the author diagnosed the syndrome of obstruction or the syndrome of incompetence in the majority of the severely disabled, but about $5 \%$ formed distinct and intermediate group. Anatomicallo, when operation was performed, the long diamet 


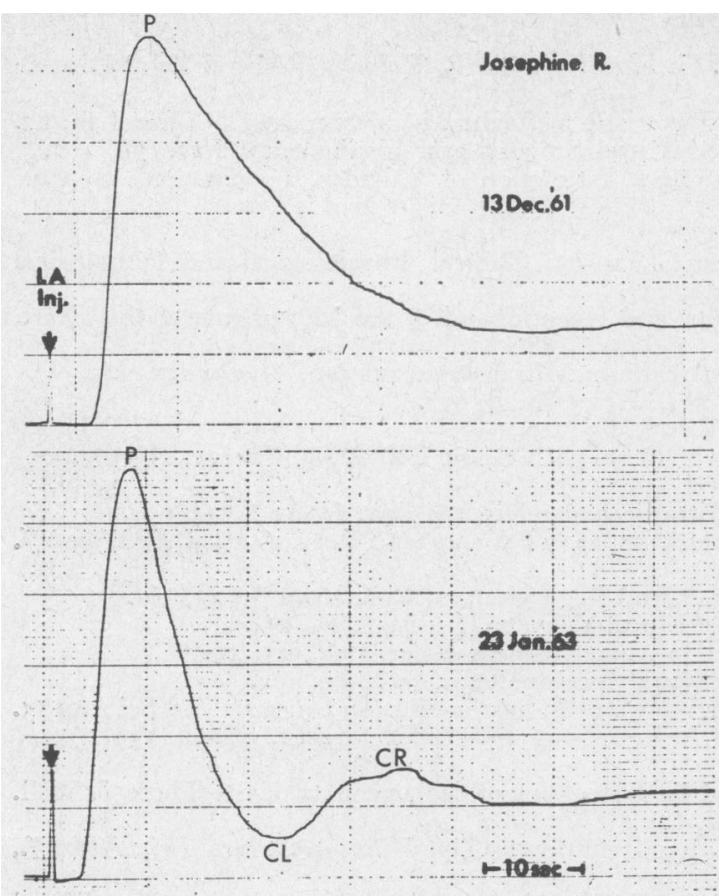

Fig. 5.-Severe mitral incompetence before and after treatment. Upper tracing: an ear-piece arterial indicator-dilution curve obtained by injecting blue dye into the left atrium. The time of injection is indicated by an arrow, and the curve shows the abnormalities typical of severe mitral incompetence. Lower tracing: the test repeated a year after the defect was treated surgically by Mr. G. H. Wooler. It displays the features of a normal curve. $\mathbf{P}=$ peak of primary circulation. $\mathbf{C R}=$ recirculation peak. $\mathrm{CL}=$ the dip of least concentration.

of the mitral orifice was found to measure about 1.5 to $2.0 \mathrm{~cm}$., and the cusps and chordæ were immobilised by dense fibrous tissue and calcification (Nixon and Wooler, 1963a).

Physiologically, the diastolic murmur resembles the murmur of severe obstruction in its beginning close to the time of opening of the mitral valve, and its presence in the rapid ventricular filling phase. However, it waxes louder at the left atrial annular ascent point, and wanes in the remainder of diastole. It does not disappear unless diastole lasts for more than about I second. Small third heart sounds occur occasionally, in a minority of cardiac cycles, and opening snaps usually are absent. The tracing of the movement of the left ventricular apex shows a small peaked wave at the time of the left atrial annular ascent point, but it never approaches the size of its counterpart in the syndrome of severe incom- petence. The equalization of the left atrial and the left ventricular pressures requires diastolic intervals of at least $I$ second, and the formation of stasis waves requires even longer intervals. Aneurysmal dilatation of the left atrium commonly causes gross distortion of the dilution curve in these patients.

\section{The surgical implications}

The patients with the syndrome of severe obstruction may be treated by mitral valvotomy, and the presence of the regurgitant jet before operation does not appear seriously to affect the result.

The author believes that valvotomy is contraindicated in the syndrome of the rigid valve, even though the component of obstruction appears to be severe; separation of the immobile cusps increases the regurgitation, allows the mitral annulus to enlarge, and leads, after one or two years, to progressive deterioration from steadily worsening regurgitation. When treated medically it seems that the patients deteriorate much more slowly than those with the syndrome of severe obstruction or severe incompetence. The rigidity of the valve prevents repair; and the insertion of a prosthesis is the only treatment possible when operation is required.

The patient with the syndrome of severe incompetence and a prominent opening snap can be treated by a form of repair that is designed to correct the enlargement of the mitral annulus and the downward displacemen $i$ of the mural cusp (Wooler and others, 1962).

\section{Summary}

Patients with severe disability from chronic rheumatic mitral valvular disease who have an apical systolic murmur of mitral regurgitation may present physiologically with the syndrome of severe obstruction, the syndrome of severe incompetence or, more rarely, with the syndrome of the rigid valve. Examination of the valve at operation shows that the long diameter of the mitral orifice measures about $1.5 \mathrm{~cm}$. or less in the first group, about $2 \mathrm{~cm}$. or more in the second, and about 1.5 to $2 \mathrm{~cm}$. in the third. The surgical treatment of the three syndromes is discussed briefly.

This work, pursued with Mr. G. H. Wooler, has been made possible by the close support of Professor R. E. Tunbridge, and the generosity of the Board of Governors of the United Leeds Hospitals, the Nuffield Foundation, the Medical Research Council and private benefactors. The author has been helped by Dr. H. Ikram and Dr. F. Hepburn, and for excellent technical assistance he is grateful to Mr. R. Addyman, Mr. H. M. Snow, Mr. H. Ketteringham and others. 


\section{REFERENCES}

Goodwin, J. F., Hunter, J. D., Cleland, W. P., Davies, L. G., and Steiner, R. E. (1955): Mitral Valve Disease and Mitral Valvotomy, Brit. med. F., ii, 573.

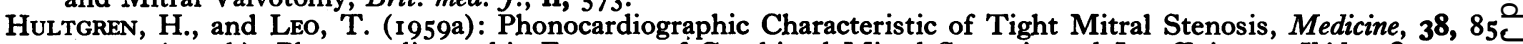

, (1959b): Phonocardiographic Features of Combined Mitral Stenosis and Insufficiency, Ibid., 38, 103.

KORNER, P. I., and SHILlingFoRd, J. P. (1955): The Quantitative Estimation of Valvular Incompetence by Dy Dilution Curves, Clin. Sci., 14, 553.

Leatham, A. (1952): Phonocardiography, Brit. med. Bull., 8, 334.

McDonald, L., Dealy, J. B., Rabinowitz, M., and Dexter, L. (1957): Clinical, Physiological and Pathologica Findings in Mitral Stenosis and Regurgitation, Medicine, 36, 237.

MACKENZIE, J. (1902): The Study of the Pulse, Arterial, Venous and Hepatic, and of the Movements of the Heart Edinburgh and London: Young J. Pentland.

Nixon, P. G. F. (1960): The Transeptal Approach to the Left Atrium in Mitral Regurgitation, Thorax, $15,225$. (1961): The Third Heart Sound in Mitral Regurgitation, Brit. Heart Y., 23, 677. (1963): The Genesis of the Third Heart Sound, Amer. Heart F., 65, 712. and IKRAM, H. (1963): Diagnosis of the Mitral Lesion in Patients with Giant Left Atria, Thorax, 18, 307. (1964): To be published.

and SNow, M. H. (1962): Indicator-dilution Curves in Mitral Valvular Disease, Brit. Heart Y., 24, 637. and Wooler, G. H. (1960): Clinical Assessment of the Mitral Orifice in Patients with Regurgitation, Brit. med. $\mathcal{Y}_{0}$ ii, II22.

\footnotetext{
- - (196r): Rapid Left Ventricular Filling and Stasis in Mitral Regurgitation, Brit. Heart Y., 23, 16 r.

- (1963a): Phases of Diastole in Various Syndromes of Mitral Valvular Disease, Ibid., 25, 393.

- - (1963b): Left Ventricular Filling Pressure Gradient in Mitral Incompetence, Ibid., 25, 382.

- - and RAdigan, L. R. (1960): The Opening Snap in Mitral Incompetence, Ibid., 22, 395 .
}

Phinney, A. O., Cotton, K., and Shillingford, J. P. (1961): Mixing and Indicator-dilution Curves, Clin. Sci., 20, 75 RADNER, S. (1957): Left Atrial Pressure Curve: Significance of Annular Ascent Wing, Acta. med. Scand., 159, 219. (1958): In Circulation, p. 250. Oxford: Blackwell.

SCHNEIDER, H., and KLUNHAAR, E. W. J. M. (1961): Precordial Low-frequency Displacements of the Thoracic Wall? Method of Recording and Registration, Amer. Heart F., 6r, 670.

ShILlingroRD, J. (1958): Simple Method for Estimating Mitral Regurgitation by Dye Dilution Curves, Brit. Heart $\mathcal{F}$. 20, 229.

Wood, E. H., and Woodward, E. (1957): A Simple Method for Differentiating Mitral Regurgitation from MitraB Stenosis by Indicator-dilution Curves, Proc. Mayo Clin., 32, 536.

WoodWARD, E., BURCHELl, H. B., and Wood, E. H. (1957): Dilution Curves Associated with Valvular Regurgitatiôn $\vec{\odot}$ Ibid., 32, 536.

Wooler, G. H., Nixon, P. G. F., Grimshaw, V. A., and Watson, D. A. (1962): Experiences with the Repair of Mitral Valve in Mitral Incompetence, Thorax, 17, 49. 